University of Nebraska - Lincoln

DigitalCommons@University of Nebraska - Lincoln

Faculty Publications from the Harold W. Manter Laboratory of Parasitology

1996

Body Size Evolution of Oxyurid (Nematoda) Parasites: The Role of Hosts

\author{
Serge Morand \\ Centre de Biologie et de Gestion des Populations, morand@ensam.inra.fr \\ Pierre Legendre \\ Universite de Montreal \\ Scott Lyell Gardner \\ University of Nebraska - Lincoln, slg@unl.edu \\ Jean-Pierre Hugot \\ Museum National d'Histoire Naturelle, hugot@cimrs1.mnhn.fr
}

Follow this and additional works at: https://digitalcommons.unl.edu/parasitologyfacpubs

Part of the Parasitology Commons

Morand, Serge; Legendre, Pierre; Gardner, Scott Lyell; and Hugot, Jean-Pierre, "Body Size Evolution of Oxyurid (Nematoda) Parasites: The Role of Hosts" (1996). Faculty Publications from the Harold W. Manter Laboratory of Parasitology. 74.

https://digitalcommons.unl.edu/parasitologyfacpubs/74

This Article is brought to you for free and open access by the Parasitology, Harold W. Manter Laboratory of at DigitalCommons@University of Nebraska - Lincoln. It has been accepted for inclusion in Faculty Publications from the Harold W. Manter Laboratory of Parasitology by an authorized administrator of DigitalCommons@University of Nebraska - Lincoln. 


\title{
Body Size Evolution of Oxyurid (Nematoda) Parasites: The Role of Hosts
}

\author{
Serge Morand, Pierre Legendre, Scott Lyell Gardner, Jean-Pierre Hugot
}

\begin{abstract}
S. Morand, Centre de Biologie et d'Écologie tropicale et méditerranéenne, Laboratoire de Biologie Animale (Unité de Recherche Associée au CNRS 698), Université de Perpignan, Avenue Villeneuve, 66860 Perpignan, France (morand@univ-perp.fr)

P. Legendre, Département de sciences biologiques, Université de Montréal, C.P. 6128, Suce. A, Montréal, Québec, Canada H3C 3J7 S. L. Gardner, H. W. Manter Laboratory of Parasitology, University of Nebraska State Museum, Lincoln, Neb. 68588-0514, USA J.-P. Hugot, Muséum National d'Histoire Naturelle, Laboratoire de Biologie parasitaire (Unité de Recherche Associée au CNRS 114b), 75231 Paris Cedex 05, France
\end{abstract}

\section{Received November 13, 1995; Accepted February 12, 1996}

\begin{abstract}
Studying the diversification of body size in a taxon of parasites allows comparison of patterns of variation observed in the parasites with patterns found in free-living organisms. The distributions of body size of oxyurid nematodes (obligate parasites of vertebrates and invertebrates) are lognormally right-skewed, except for male oxyurids in invertebrates which show left-skewed distributions. In these parasitic forms, speciose genera do not have the smallest body sizes. Parasite body size is positively correlated with host body size, the largest hosts possessing the largest parasites. This trend is shown to occur within one monophyletic group of oxyurids, those of Old World primates. Comparative methods are used to take account of the effects of phylogeny. The use of multiple linear regression on distance matrices allows measurements of the contribution of phylogeny to the evolution of body size of parasites. Evolution of body size in female pinworms of Old World primates appears to be dependent only on the body size of their hosts. The tendency of parasite body size to increase with host body size is discussed in the light of the evolution of life-history traits.
\end{abstract}

\section{Introduction}

Variation in body size is one of the most biologically important and conspicuous traits of the metazoa, the size of an organism influencing almost all aspects of its biological and behavioural characteristics (Sibly and Calow 1986; Naganuma and Roughgarden 1990; Harvey and Pagel 1991; Kozlowki 1992; Steams 1992; Charnov 1993). During phylogenesis, size traits of organisms show tremendous diversification, patterns of variation in size occurring both within and among related species. Understanding the processes and mechanisms whichproduce patterns of variation in body size in phylogenetically related species is one of the central questions in morphologically based studies of evolution (Hutchin-

Key words: body size, host-parasite relationship, lognormally skewed distribution, nematodes, independent comparisons, Cope's rule. son and MacArthur 1959; Lewin 1983; Maureret al. 1992).

The apparent tendency of body size to increase over time in many taxonomic groups of organisms is known as Cope's rule (Stanley 1973). Different models have been proposed to explain this phenomenon and studies of natural or artificial selection indicate that microevolutionary processes operating through differential survival and reproduction could lead to an evolutionary change in the body size of a species. Larger individuals are often thought to accrue ecological advantages such as increased ability to compete for resources, or a selective advantage for larger body size in predator-prey relationships. Macroevolutionary explanations for variation in body size invoke differential extinction and speciation within and among lineages (Gould 1988). Stanley (1973) invokes a macroevolutionary hypothesis in testing Cope's rule, by arguing that the ancestor of a lineage may have a small body size and a simple increase of variance of the size through cladogenesis could explain the actual distribution of body sizes among phylogenetically related species.

May (1978) stated that small organisms are taxonomically more diverse than large organisms because small individuals are more capable of exploiting their environment in a fine-grained way. However, Dial and Marzluff (1988) showed that organisms with intermediate body sizes have greater taxonomic diversity. They failed to reject the hypothesis that "... through evolutionary time, extinction of taxa with extreme sizes and radiation of small taxa leads to a preponderance of small, but not the smallest, sized taxa."

Parasites provide an ideal model for testing ecological constraints, such as the size of the host, on the evolution of body size in a group of organisms (Harvey and Keymer 1991; Poulin 1995b). Changes in body size related to evolution towards parasitism follow diverse trends depending on the parasite group. For instance, increase in body size with switching towards parasitism is observed for nematodes (Kirchner et al. 1980) while decrease in body size occurs in isopods (Poulin 1995a).

Nematode parasites of the order Oxyurida have not 
yet been used in studies of evolution of body size. We consider this group of nematodes an excellent model for comparisons with free-living organisms because of the extremely intimate relationship that exists between the hosts and their parasites (Adamson 1989). Because of this, the body size of these parasitic nematodes may be strongly influenced by the body size of their hosts.

By analyzing the evolution of body size of parasites, we want to answer two primary questions: (1) What is the pattern of distribution of body sizes in a phylogenetic lineage? (i.e. what is the general pattern of morphological size-diversification, and are the smallest organisms the most diverse?) (2) Is the body size of parasites correlated with that of their hosts? To get a clear answer to this question, the influence of the phylogeny of the relation between body sizes of hosts and those of their parasites must be assessed.

\section{Materials and methods}

\section{The data}

A data base was assembled on 605 species of Oxyurida, from original descriptions of species and from the summary books of Skrjabin et al. (1960) and Leibersperger (1960). Information on egg size, female body size and male body size was complete for only 461 species (Table 1). Measurements of hosts (maximum length) were taken from Walker (1968), Pasteur and Bons (1959, 1960), and Dawling (1966), and also obtained from specialists of the Muséum d'Histoire Naturelle of Paris. Data on invertebrate hosts are often missing.

\section{Biology of the parasites}

More than 600 species of the order Oxyurida have been described, representing 11 families parasitizing both invertebrates and vertebrates. Most are highly host-specific (Table 1).

Despite this great diversity in hosts, the life cycle remains identical in all oxyurid species. Adult worms inhabit the digestive tract of herbivorous or, more rarely, omnivorous hosts. In the generalised oxyurid life cycle, females produce eggs which exit the host with feces. In the external environment, embryonic development continues up to the second juvenile stage, the egg then becoming capable of infecting a new host. All oxyurids that have been studied have a direct life cycle; eggs hatch only after being ingested by a host and juveniles complete two more moults in the host digestive tract. These nematodes are characterised by a haplo-diploid mode of reproduction, as only recently discovered by Adamson $(1989,1990)$. Females are produced from fertilised eggs, while males develop from unfertilised ova. Males are smaller than females, and a correlation between haplodiploidy and sexual dimorphism has been postulated by Adamson (1989).

Unfortunately, the biological characteristics and phylogenetic relationships of the oxyurids are not well known. Life cycles, with information on rate of maturation of females, have been described from fewer than ten species. Host-parasite coevolution using phylogenetic methods has been studied in only a handful of the Oxyurida (Brooks and Glen 1982; Hugot 1988, 1990). It is not possible to generalise about levels of cospeciation from these

Table 1 Taxonomy of Oxyurida with numbers of genera and species in each family, host groups and mean body lengths of oxyuroid males and females. This taxonomy is based on Adamson (1989), Hugot (1988, 1990), Petter and Quentin (1975) and Poinar (1977)

\begin{tabular}{|c|c|c|c|c|}
\hline Taxa of Oxyurida & $\begin{array}{l}\text { Number of genera } \\
\text { (number of species) }\end{array}$ & Host groups & $\begin{array}{l}\text { Mean body length } \\
\text { of female in }(\mu \mathrm{m}) \\
( \pm \text { SD and range })\end{array}$ & $\begin{array}{l}\text { Mean body length } \\
\text { of male in }(\mu \mathrm{m}) \\
( \pm \mathrm{SD} \text { and range) }\end{array}$ \\
\hline Chitwoodliellidae & $8(14)$ & Insects, Diplopods & $\begin{array}{l}2917 \pm 1478 \\
(1330-6980)\end{array}$ & $\begin{array}{c}1087 \pm 382 \\
(660-1790)\end{array}$ \\
\hline Hystrignathidae & $9(18)$ & Insects & $\begin{array}{c}2970 \pm 953 \\
(1700-4790)\end{array}$ & $\begin{array}{c}910 \pm 171 \\
(720-1050)\end{array}$ \\
\hline Protrelloididae & $4(13)$ & Insects & $\begin{array}{c}5070 \pm 2143 \\
(2620-10370)\end{array}$ & $\begin{array}{c}759 \pm 506 \\
(270-1730)\end{array}$ \\
\hline Pseudonymidae & $4(15)$ & Insects & $\begin{array}{c}3146 \pm 906 \\
(1751-4675)\end{array}$ & $\begin{array}{c}1226 \pm 201 \\
(932-1500)\end{array}$ \\
\hline Thelastomatidae & $28(93)$ & Insects, Oligochaetes, Diplopods & $\begin{array}{c}3495 \pm 1759 \\
(1335-14400)\end{array}$ & $\begin{array}{l}1162 \pm 468 \\
(410-2700)\end{array}$ \\
\hline Pharyngodonidae & $23(185)$ & Fishes, Amphibians, Reptiles, Aves, Rodents & $\begin{array}{c}4624 \pm 2120 \\
(1900-23500)\end{array}$ & $\begin{array}{l}2591 \pm 1138 \\
(677-9600)\end{array}$ \\
\hline Oyuridae & $4(13)$ & Perissodactyls, Artiodactyls & $\begin{array}{l}13350 \pm 15516 \\
(1500-90000)\end{array}$ & $\begin{array}{c}6205 \pm 3667 \\
(660-14200)\end{array}$ \\
\hline Heteroxynematidae & $11(50)$ & Aves, Rodents, Lagomorphs & $\begin{array}{c}6315-3650 \\
(2220-21400)\end{array}$ & $\begin{array}{c}2283 \pm 994 \\
(1035-5700)\end{array}$ \\
\hline Citellinidae & $5(25)$ & Dermopters, Marsupials & $\begin{array}{c}7276 \pm 2726 \\
(3515-13400)\end{array}$ & $\begin{array}{l}3731 \pm 1715 \\
(1100-7000)\end{array}$ \\
\hline Trypanoxyuridae & $5(48)$ & Primates, Rodents & $\begin{array}{c}6315 \pm 3650 \\
(2220-21400)\end{array}$ & $\begin{array}{c}2283 \pm 994 \\
(1035-5700)\end{array}$ \\
\hline Syphaciidae & $16(97)$ & Rodents, Lagomorphs & $\begin{array}{c}7594 \pm 6359 \\
(1430-40000)\end{array}$ & $\begin{array}{l}2864 \pm 2175 \\
(880-13400)\end{array}$ \\
\hline
\end{tabular}


few studies and more work in this area is needed. Cospeciation events may be frequent, as in the pinworm-primate (Brooks and Glen 1982; Brooks and McLennan 1993) and the pinworm-rodent assemblages (Hugot 1988, 1990).

\section{Analysis}

Because of the diversity of host taxa used by oxyurids, host length may be a poor comparative measure of host body size. Length may be related to mass in very different ways in different host groups (Peters 1983). However, body mass is very sensitive to environmental conditions in invertebrates (Hopkin and Read 1992; Kooijman 1993). It is also very difficult to obtain information on body mass of invertebrates, so we decided to use host length in our comparative analysis.

We used the methodology of Maurer et al. (1992) to address the question of selection favouring either small or large sizes in oxyurids. The lengths of male and female parasites were log-transformed (ln) and the skewness of distributions was calculated. This coefficient is equal to zero for non-skewed (i.e. symmetrical) distributions. We tested for significant departures from zero using Student's Mest based upon the standard error of the coefficient of skewness (Sokal and Rohlf 1981). Skewness of (ln body sizes) was calculated and tested for males and females among species and genera of oxyurids, from vertebrate and invertebrate hosts.

All data were $\ln$ transformed (Harvey 1982). MA (major axis) regressions were performed. When neither dependent nor independent variables are controlled, model II regression (MA or RMA) should be applied to estimate the functional relationship between two variables, because the slope found by the ordinary least-squares method may be biased (Legendre and Legendre 1996). The MA method has no systematic bias according to Legendre and Legendre (1995). Since both variables in each regression are random (i.e. measured with error), both are in In scale, and we are interested in describing the functional relation between them, major axis regression (MA) was used (Pearson 1901; Jolicoeur and Mosimann 1968; Jolicoeur 1973; Sokal and Rohlf 1981). The regression line computed by this method is actually the first principal component of the scatter of points; $95 \%$ confidence intervals (CI) of the slope parameter were also computed, allowing testing of the null hypothesis that the slope of the relationship between the two variables is zero.

Evolution of body size in relation to host size was examined in the genus Enterobius, for which phylogenies are known (Brooks and Glen 1982; Brooks and McLennan 1993).

To address the question of whether the body size of parasites is correlated with the body size of their hosts, one has to take para- site phylogeny into account. An observed correlation between parasite and host sizes might be spurious, resulting from the fact that phylogenetically related species of parasites tend to infest hosts of about the same size. In general, closely related species are more likely to exhibit similar development than distant species; this is a consequence of the "taxon-level effect" (Pagel and Harvey 1988). We are looking instead for a correlation between host and parasite body sizes that would result from a functional microevolutionary process by which parasites would have evolved larger body sizes in larger hosts. A number of "comparative methods" have recently been proposed to take this possibility into account, considering the phylogeny fixed and controlling for its effect in order to study the correlation among traits; they have been summarised by Harvey and Pagel (1991).

To take account of the effects of phylogeny we use the methodofindependentcontrasts (Felsenstein1985; seealso Burt1989). WeusetheCAIC program(Purvisand Rambaut 1994, 1995). Regressions performed on phylogenetically independent contrasts were forced through the origin.

In the present paper, we also use a multiple regression method on distance matrices. This method was recently proposed by Legendre et al. (1995) to "explain" matrices representing either plain distances, dendrograms or cladograms, using other matrices also representing plain distances, dendrograms or cladograms. The coefficient of determination of the multiple regression, as well as the partial regression coefficients, are tested for significance through permutation methods appropriate for each type of dependent matrix-variable. The regression method is thus naturally extended to the problem of controlling for the effect of a phylogeny in studying the correlation among traits.

1. The dependent variable, size of parasites, is transformed into a distance matrix $Y$ by computing the "distance" among size values (absolute value of the difference, which is also equal to the Euclidean distance among values).

2. Similarly, the host size variable is turned into a "distance" matrix X1.

3 . The parasite phylogeny is represented in the analysis by a matrix X2 of patristic distances among species; since no segment length estimations are available, patristic distances are computed as the number of segments along the evolutionary tree that separate two species.

4. A multiple regression is computed with $\mathrm{Y}$ as the dependent variable.

5. Regression coefficients are obtained for $\mathrm{X} 1$ and $\mathrm{X} 2$ and tested for significance using the method for simple dependent distance matrices of Legendre et al. (1995). Multiple regression coefficients are actually partial regression coefficients (Sokal and Rohlf 1981, p. 620). For instance, the regression coefficient of $\mathrm{X} 2$ in our equation describes the partial effect of parasite phylogeny on differences in parasite sizes, after controlling for the effect of differences in size of hosts.

6. Probabilities were computed after 999 random permutations of the distance matrix; the lowest attainable probability value is therefore 0.001 . The values in both dis- 
tance matrices were standardised before computing the regression, so that there is no intercept and the regression coefficients become standard regression coefficients.

A major advantage of this method over the comparative techniques is that the multiple regression on distance matrices provides an estimate of the contribution of the phylogeny to the structure of the dependent variable, as well as that of the independent variable to be tested. Other comparative techniques do not offer this benefit.

\section{Results}

\section{Distribution of parasites among host groups}

Representatives of five families of Oxyurida occur in invertebrates (insects, oligochaetes, and diplopods); our data represent 153 species and 53 genera (Table 1). Species of six families are parasites of vertebrates; 418 species of 64 genera are included in our data base.

\section{Patterns of body size distribution of oxyurids}

Small body sizes of parasitic nematodes are found in species occurring in invertebrates (Table 1). The largest body sizes occur in species of oxyurids found in the ungulates

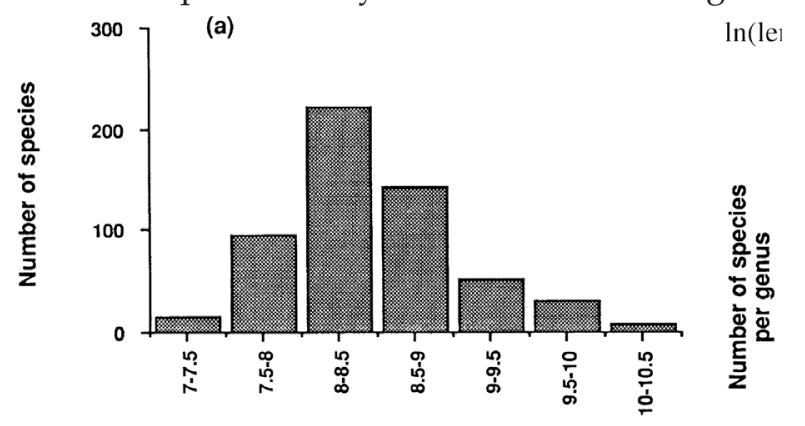

Ln (Length of Females)

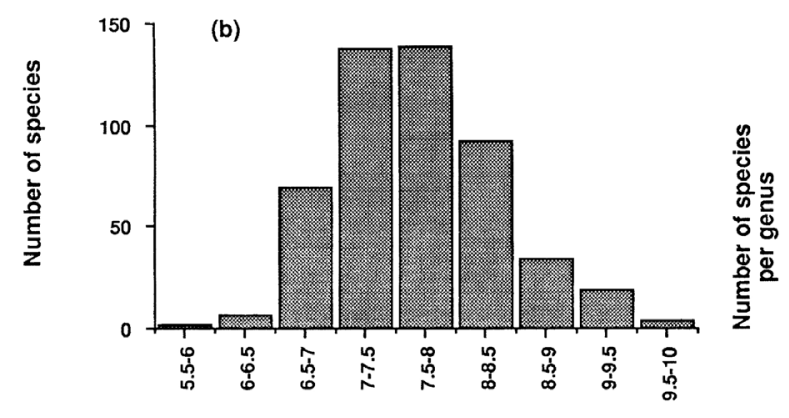

Ln (Length of Males)

Figures 1a, $\mathbf{b}$ Ln body size ( $\mathrm{mm}$ ) distribution of oxyurid $\mathbf{a}$ females and $\mathbf{b}$ males. Both distributions are skewed towards species of large body size (mammalian suborders Artiodactyla and Perissodactyla). The distribution of $\ln$ body size of female oxyurid species is statistically positively skewed, which means that there are more species with body size larger than the mode than expected in a symmetric distribution. An alternative but equally adequate description is that the mode is on the left of the mean body size value (Figure 1, Table 2). A similar pattern is found in males, except for those from invertebrate hosts, which have a negatively skewed distribution (mode larger than the mean). In the case of genera, the distribution of (log body size) is also positively skewed (Table 2); no difference was detected between host types.

The most diverse genera of oxyurids, appreciated in terms of number of species, are not the smallest (Figure 2).

\section{Importance of host body size}

In this part of the analysis, we examine the relationship between the body sizes of the hosts and parasites. All data were logarithmically transformed (Figure 3).

Two MA regression equations were obtained. The first one links female parasite body size to host body size:

$\ln ($ length of female $)=0.643 \ln ($ length of host $)+5.118$
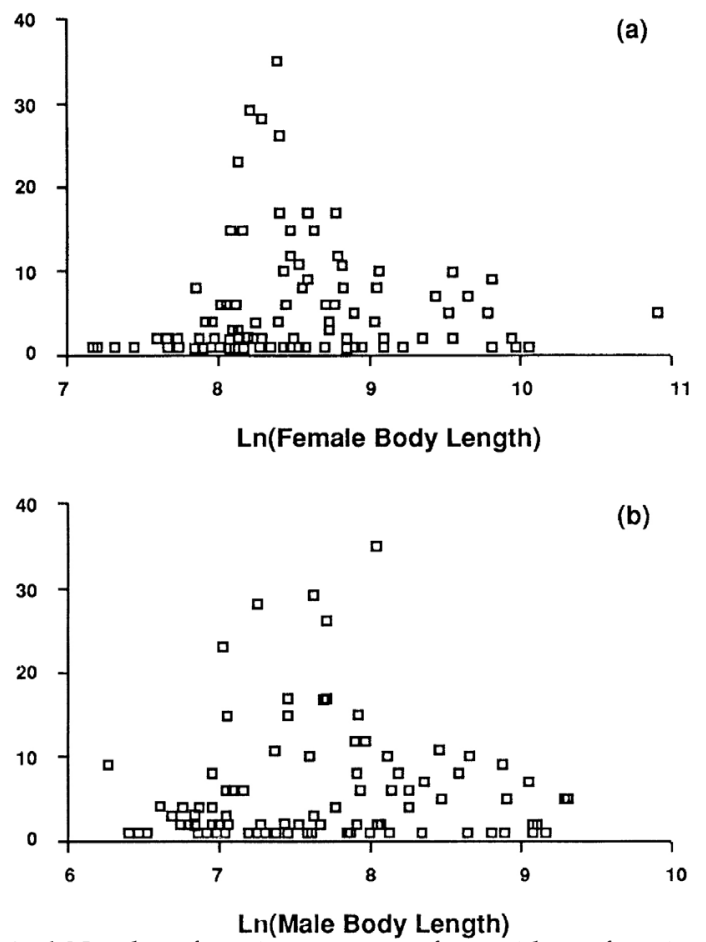

Figures 2a, $\mathbf{b}$ Number of species per genus of oxyurids as a function of average body size (lnsize, $\mathrm{mm}$ ) of species ineach genus for $\mathbf{a}$ females, $\mathbf{b}$ males
Table 2 Skewness of $\ln$ length (size) of females and males among species and genera of oxyuroids

${ }^{*} P>0.05$, reject $(\mathrm{H} 0$ : skewness not different from 0 )

\begin{tabular}{|l|l|l|l|l|l|l|l|}
\hline & & $n$ & Species skewness & SE & $n$ & Genera skewness & SE \\
\hline All hosts & Female & 571 & $1.01^{*}$ & 0.10 & 114 & $0.85^{*}$ & 0.23 \\
\hline & Male & 468 & $0.35^{*}$ & 0.11 & 97 & $0.57^{*}$ & 0.24 \\
\hline Invertebrate hosts & Female & 153 & $0.46^{*}$ & 0.20 & 55 & -0.15 & 0.32 \\
\hline & Male & 107 & $-0.45^{*}$ & 0.23 & 42 & 0.12 & 0.37 \\
\hline Vertebrate hosts & Female & 419 & $1.08^{*}$ & 0.12 & 38 & 0.05 & 0.38 \\
\hline & Male & 364 & $0.57^{*}$ & 0.13 & 38 & 0.16 & 0.38 \\
\hline
\end{tabular}



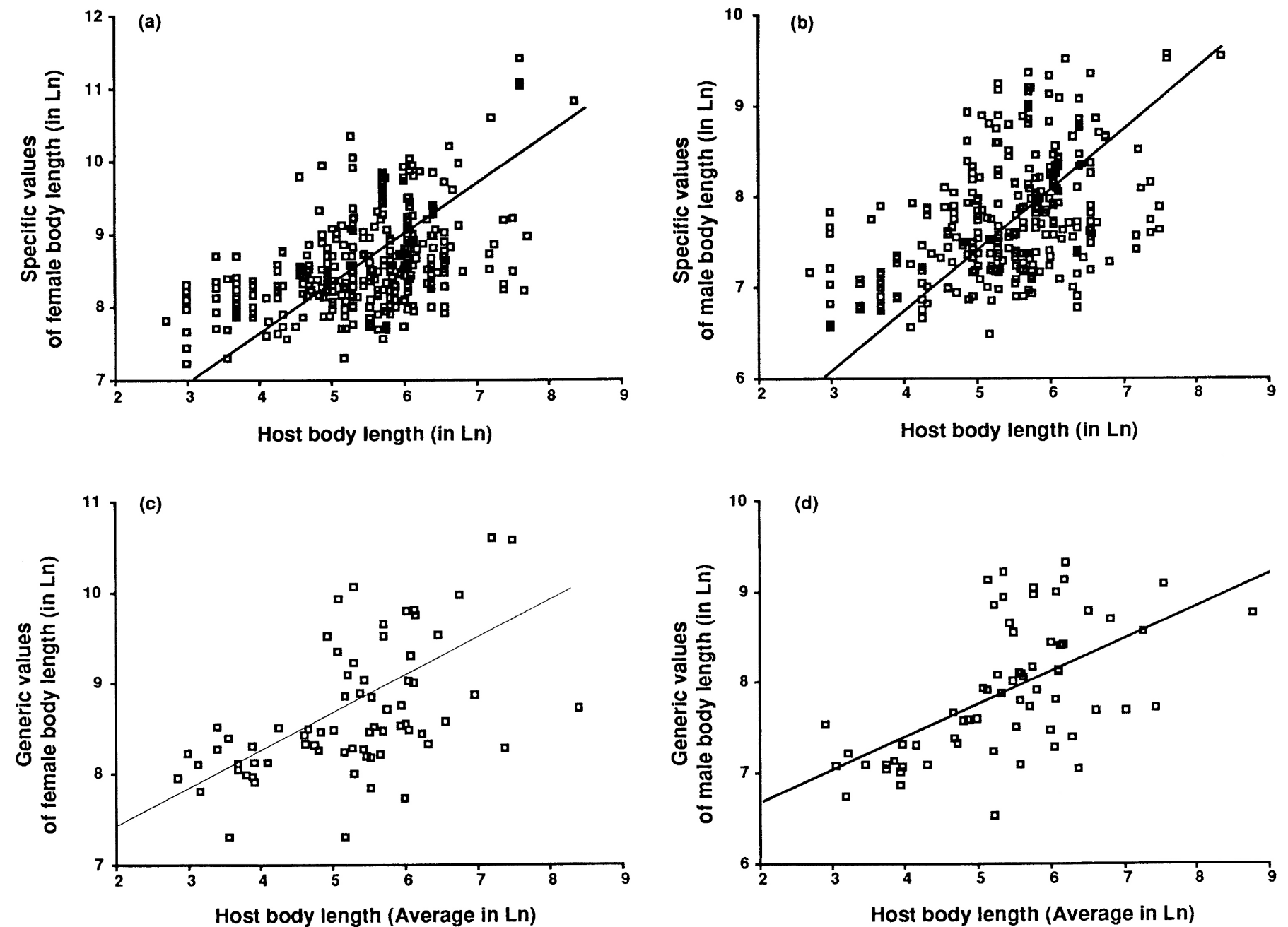

Figures 3a-d Relationships between $\ln$ body length of hosts $(\mathrm{mm})$ and specific values of $\mathbf{a}$ ln body size of oxyurid females (mm) and $\mathbf{b} \ln$ body size of oxyurid males ( $\mathrm{mm}$ ). Relationships between generic values of $\mathbf{c} \ln$ body size of oxyurid females ( $\mathrm{mm}$ ) and $\mathbf{d} \ln$ body size of oxyurid males (mm), and average $\ln$ body length of hosts $(\mathrm{mm})$. The major axis (MA) regression lines are shown.

with $95 \%$ CI of slope $=(0.584,0.706)$. So, the slope differs significantly from zero. The second MA equation links male parasite body size to host body size:

$\ln ($ length of male $)=0.684 \ln ($ length of host $)+4.072$

with $95 \%$ CI of slope $=(0.618,0.756)$. The slope is significantly different from zero, but does not differ from the slope of the female-to-host body size relationship (0.643).

Similar relationships were found for values of parasite body size averaged per genus:

$\ln$ (average length of female $)=0.406 \ln$ (average length of host) +6.532

with $95 \%$ CI slope $=(0.253,0.578)$

$\ln$ (average length of male $)=0.462 \ln$ (average length of host) +5.395

with $95 \%$ CI slope $=(0.307,0.638)$

Thus, it appears that body size of parasites increases significantly with host body size. Larger hosts have larger pinworm parasites. Similar trends found both in cross-species and cross-genus correlations to exclude a phylogenetic artefact.

Importance of host body size: the oxyurids of Old World primates

The hypothetical phylogeny of the oxyurids of Old World primates has been developed by Brooks and Glen (1982) and Brooks and McLennan (1993) (Figure 4).

The results of ordinary regressions performed on crossspeciesandindependentcontrastsofhostand parasitebody sizes are reported in Figure 5. Both regressions show significant increase of parasite body sizes with host body sizes.

We used the regression method on distance matrices to test the effect, on parasite body size, of both host body size (X1) and parasite phylogeny ( ) (Table 3). We found the following significant linear relation linking the matrix of distances among female parasite body sizes (Y) to the distance matrix among host body sizes (X1):

distances among female parasite body sizes $=0.487 \mathrm{x}$ distances among host body sizes. 
Figure 4 Phylogeny of the oxyurids of Old World primates. Redrawn from Brooks and Glen (1982)
Parasites

Hosts

Lemuricola inglisi

Lemur sp.

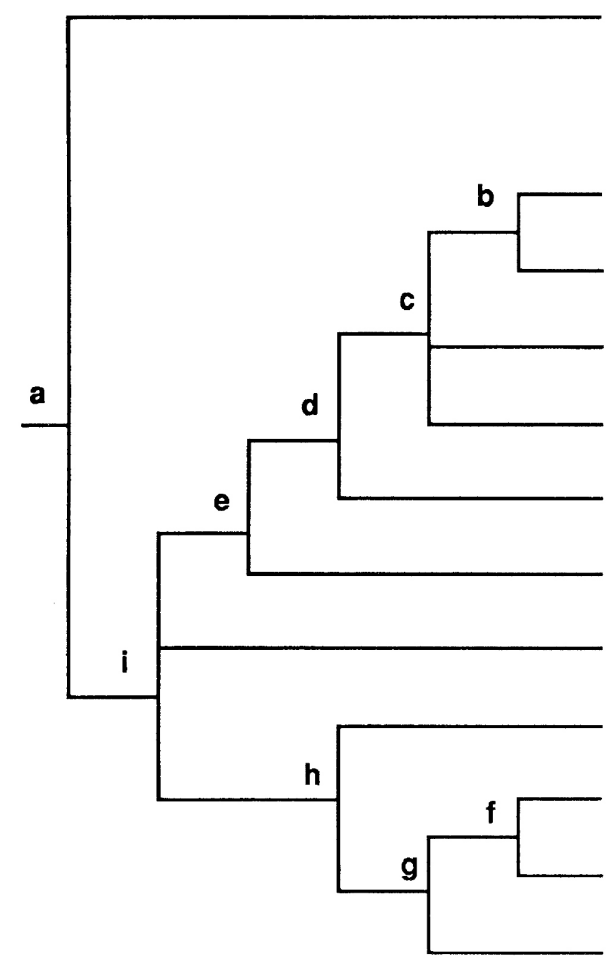

Enterobius zakiri

Enterobius longispiculum

Enterobius presbytis

Enterobius pesteri

Enterobius colobis

Enterobius brevicaudata

Enterobius bipapillatus

Enterobius vermicularis

Enterobius anthropitheci

Enterobius lerouxi

Enterobius buckleyi
Presbytis entellus

P. obscura

P. phayrei

Colobus sp.

C. badius

Papio sp.

Cercopithecus sp.

Homo sapiens

Pan troglodytes

Gorilla gorilla

Pongo pygmeus
$\left(R^{2}=0.238, P=0.031\right)$. We are especially interested here in the significance of the relationship. The actual value of the regression parameter is of little interest; it would only be useful for prediction purposes. As for the functional relationship, the slope of the MA regression equation among distance matrices would be 1 since both matrix variables have been standardised prior to the calculations.

In the case of male parasites, we found the following multiple regression equation with all terms significant (Table 3):

distances among male parasite body sizes $=0.505 x$ distances among female parasite body sizes -0.317 distances among host body sizes

$\left(R^{2}=0.203, P=0.024\right)$.

\section{Discussion}

Nematodes of the order Oxyurida include numerous species that infect a wide range of hosts, from invertebrates to vertebrates. No other groups of helminth parasites occur as sexually reproducing adults in such a wide diversity of hosts. The study of diversification of body size in this parasite group allows us to compare observed patterns in the parasites with patterns of variation in free-living organisms. Statistical bias is not completely excluded, because the nematode fauna of vertebrates is much better known than the fauna of invertebrates, but our large sample size (153 species of oxyurids in invertebrates) may strongly reduce it.
Body size distributions of oxyurid nematodes are lognormal and right-skewed. These distributions are observed both in vertebrate and invertebrate hosts, except for male oxyurids of invertebrates which show a leftskewed distribution (towards small body size). This pattern is similar to those exhibited by free-living nematodes which also show a lognormally right-skewed distribution of body sizes as pointed out by Kirchner et al. (1980).

Maurer et al. (1992) constructed a simulation model to test both micro- and macroevolutionary hypotheses about the evolution of body size. The first hypothesis explains the change of body size by differential adaptation of individuals to their environment. The macroevolutionary hypothesis deals with rapid body-size changes through phases of speciation. The simulation model of Maurer et al. (1992) clearly shows that lognormal rightskewed distributions of body size are not obtained only by macroevolutionary processes, i.e. by differential rates of extinction/ survival of taxa within a lineage. The rightskewed distribution of body sizes of the Oxyurida, similar to those distributions found in mammals and birds, suggests that adaptive processes play a significant role.

Taxonomic diversity is appreciated by studying the distribution of species/genera relative to average body size. The distributions of species/genera observed both in vertebrate and invertebrate hosts are right-skewed. Parasite genera with the most species are not the smallest-sized taxa. Parasites which are believed to live in a relatively stable and predictable environment (according to Jennings and Calow 1975) show a pattern of body 
(a)
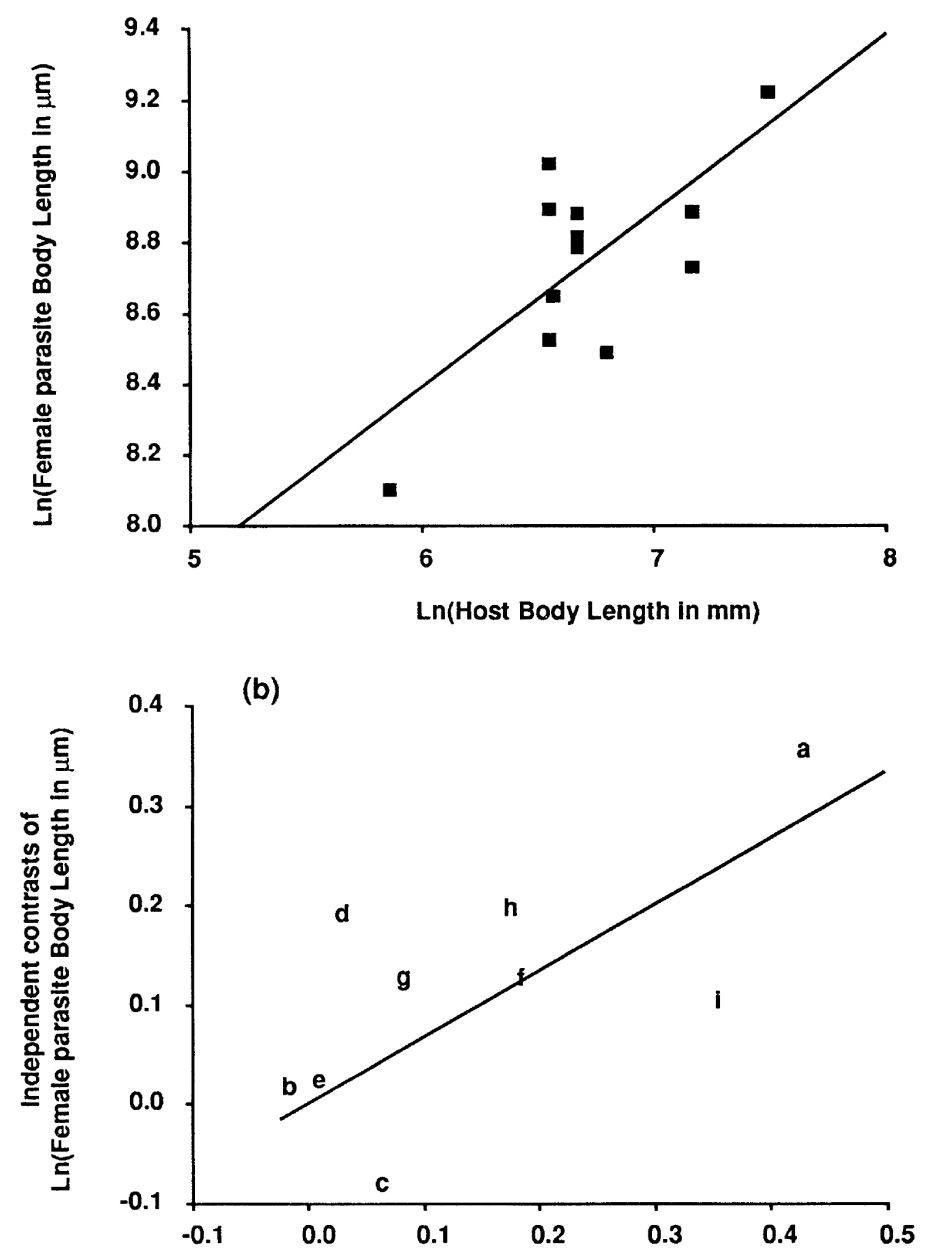

Independent contrasts of Ln(Host Body Length in $\mathrm{mm}$ )

Figures ba, $\mathfrak{b}$ ine relationsnips between temale parasite boay sizes (In) and host body size (ln). a The ordinary regression performed on crossspecies comparions gives: slope $=0.487 \pm 0.155(d f=11, P=0.009)$ (shown in figure). $\mathbf{b}$ The regression performed on independent contrasts (OLS without intercept) gives: slope $=0.662 \pm 0.159(d f=8, P=0.003)$ (shown in figure; letters refer to nodes of the phylogeny given in Figure 4)

size distribution comparable to that shown by free-living nematodes (Kirchner et al. 1980). This is interesting in itself because of the potential for testing hypothesis of body size of organisms correlated with habitat heterogeneity and the problems of scaling. This also highlights the fact that, contrary to Jenning and Calow's claim, parasites are exposed to a relatively large degree of environmental heterogeneity, both during their life cycles, and as populations living in discontinuous habitat (hosts).

We have shown a link between parasite and host body sizes. Parasite body size is positively correlated with host body size; larger hosts have larger parasites, and selection may be at work to maintain this pattern. This pattern was found by Harvey and Keymer (1991) in the case
Table 3 Backward elimination procedure of the distance matrix method for selecting an optimal subset of explanatory matrix-variables for the female and the male parasite body length $(\mathrm{mm}, \mathrm{ln})$ of Old World primates (Std. $b$ the standard partial regression coefficient). All probabilities ( $P$, one-tailed), are computed after 999 random matrix permutations of the dependent matrix-variable. At each step, the variable with the largest probability is eliminated if its probability is larger than the Bonferroni-corrected significance level $\left(\alpha^{\prime}=0.05 /\right.$ number of variables in the model at the given step)

\begin{tabular}{|l|l|l|}
\hline Dependent matrix-variable & Step 1 & Step 2 \\
\hline Independent matrix-variables & Std. $\mathrm{b}(P)$ & Std. b $(P)$ \\
\hline Female body size & & \\
\hline Host weight $(\mathrm{g}$, ln $)$ & $0.442(0.085)$ & $\mathbf{0 . 4 8 7}(\mathbf{0 . 0 0 6})$ \\
\hline Parasite phylogeny & $0.094(0.291)$ & \\
\hline$R^{2}(P)$ & $0.244(0.056)$ & $\mathbf{0 . 2 3 8}(\mathbf{0 . 0 3 1})$ \\
\hline Male body size & & \\
\hline Host weight $(\mathrm{g} . \ln )$ & $-0.317(0.005)$ & $\mathbf{- 0 . 3 1 7 ( \mathbf { 0 . 0 0 5 } )}$ \\
\hline Parasite female body size & $0.505(0.006)$ & $\mathbf{0 . 5 0 5}(\mathbf{0 . 0 0 6})$ \\
\hline Phylogeny & $0.047(0.398)$ & \\
\hline$R^{2}(P)$ & $0.204(0.036)$ & $\mathbf{0 . 2 0 3 ( \mathbf { 0 . 2 0 4 } )}$ \\
\hline
\end{tabular}

of pocket gophers and their associated chewing lice and in the case of primates and their pinworms. In their study independent comparisons were obtained by assuming co-speciation between hosts and parasites. The method of Legendre et al. (1995) does not need this assumption.

We have found that if lateral transfers of a parasites occur from one host species to another, or parasites transfer vertically during speciation of hosts, any change in host body size has a correlated effect on parasite body size. A correlated increase of body size of female parasites with that of their hosts does not necessarily contradict Cope's rule. Indeed, we would emphasise here that nematode parasites of invertebrates started to diversify a long time before the evolution of parasites in vertebrates began (Adamson 1989).

Here we have also shown that slopes of MA regressions of parasite female body sizes on host body sizes are similar in a monophyletic group of oxyurids for which phylogeny is known, the oxyurids of Old World primates (0.913). These results are the same as those presented by Harvey and Keymer (1991) except that length is used here as a measure of host body size instead of mass. The phylogeny of parasites does not appear to play any role in female pinworms of Old World primates. The evolution of male body size is also independent of phylogeny.

The evolution of parasite life-history traits has not been widely investigated. Some studies have tried to explain the variation of life-history according to $\mathrm{r}-\mathrm{K}$ theory (Esch et al. 1977) while others have emphasised the importance of trade-offs between fecundity and reproductive lifespan (Wharton 1986). The studies of Keymer et al. (1991) and Skorping et al. (1991) investigate the selective pressures driving the evolution of life-history traits of parasitic nematodes. Morand (1996b) investigated the evolution of life-history traits in free-living, plant, insect and vertebrate parasite nematodes. The allometries of lifehistory traits with body size were calculated, in partic- 
ular the allometry between size and fecundity (Morand 1996a, b). The prepatent period of parasites, or the maturation time in free-living nematodes, is correlated with body size (Morand 1996b). This indicates that delaying reproduction is associated with large body size. Because large body size is correlated with high fecundity, a fecundity advantage is thus associated with delaying maturity as pointed out by Skorping et al. (1991) and Keymer et al. (1991). A similar correlation between mortality rate and age at maturity (or prepatent period) is found in both free-living and parasitic nematodes (Morand 1996b). This suggests that the adult mortality rate might be the central factor that drives the evolution of parasite life-history traits. The maturation of the parasites within their hosts (prepatent period) occurs at the age that maximises lifetime reproductive success. Because larger hosts provide more energy and live longer, they can favour longer-lived parasites and thus can determine the parasites' adult body size, as pointed out by Harvey and Keymer (1991), and ultimately their lifetime reproductive output.

\section{Acknowledgements}

We thank Robert May for comments and encouragement on the first draft of this article, Andy Purvis for providing the computer program CAIC and helpful discussions, and Philippe Casgrain for providing the computer program Permute! We also thank Robert Poulin and an anonymous referee for their helpful comments.

\section{References}

Adamson ML (1989) Evolutionary biology of the Oxyurida (Nematoda): biofacies of a haplodiploid taxon. Advances in Parasitology 28: 175-228.

Adamson M L (1990) Haplodiploidy in the Oxyurida: decoupling the evolutionary processes of adaptation and speciation. Annales de Parasitologie Humaine et Comparee 65 Supplement 1: 31-35.

Brooks DR, Glen DR (1982) Pinworms and primates: a case study in coevolution. Proceedings of the Helminthological Society of Washington 49: 76-85.

Brooks DR, McLennan DA (1993) Parascript (Smithsonian series in comparative evolutionary biology). Smithsonian Institution, Washington.

Burt A (1989) Comparative methods using phylogenetically independent contrasts. Oxford Survey of Evolutionary Biology 6: 33-53.

Charnov EL (1993) Life History Invariants: Some Explorations of Symmetry in Evolutionary Ecology. Oxford University Press, Oxford.

Dawling MG (1966) Catalogue of American Amphibians and Reptiles. American Society of Icthyologists and Herpetologists, New York.

Dial KP, Marzluff JM (1988) Are the smallest organisms the most diverse? Ecology 69: 1,620-1,624.

Esch GW, Hazen TC, Aho JM (1977) Parasitism and r- and Kselection. In: Esch GW (ed.) Regulation of Parasite Populations. Academic Press, New York, pp. 9-62.

Felsenstein J (1985) Phylogenies and the comparative method. American Naturalist 125: 1-15.
Gould SJ (1988) Trends as changes in variance: a new slant on progress and directionality in evolution. Journal of Paleontology 62: 319-329.

Harvey PH (1982) On rethinking allometry. Journal of Theoretcial Biology 95: 37-41.

Harvey PH, Keymer AE (1991) Comparing life histories using phylogenies. Philosophical Transactions of the Royal Society of London B. 332: 31-39.

Harvey PH, Pagel M (1991) The Comparative Method in Evolutionary Biology. Oxford University Press, Oxford.

Hopkin SP, Read HJ (1992) The Biology of Millipedes. Oxford University Press, Oxford.

Hugot JP (1988) Les nématodes Syphaciinae parasites de rongeurs et de lagomorphes: taxonomie, zoogéographie, évolution. Mémoirs de Muséum Naturelle d'Histoire National Paris, Sér A Zoologie 141: 1-153.

Hugot J-P (1990) The Syphaciinae (Oxyuridae, Nematoda) parasitic in rodents and lagomorpha. Numerical taxonomy. Cladistic analysis of evolution. Annales de Parasitologie Humaine et Comparee 65 Supplement 1: 27-29.

Hutchinson GE, Mac Arthur RH (1959) A theoretical ecological model of size distributions among species. American Naturalist 93: 117-123.

Jennings JB, Calow PC (1975) The relationship between high fecundity and the evolution of entoparasitism. Oecologia 21: 109-115.

Jolicoeur P (1973) Imaginary confidence limits of the slope of the major axis of a bivariate normal distribution: a sampling experiment. Journal of the American Statistical Association 68: 866-871.

Jolicoeur P, Mosimann JE ( 1968) Intervalles de confiance pour la pente de l'axe majeur d'une distribution normale bidimensionnelle. Biom.-Praxim 9: 121-140.

Keymer AE, Gregory RD, Harvey PH, Read AF, Skorping A (1991) Parasite-host ecology: case studies in population dynamics, life-history evolution and community structure. Acta Oecologia 12, 105-118.

Kirchner TB, Anderson RV, Ingham RE (1980) Natural selection and the distribution of nematode sizes. Ecology 61: 232237.

Kooijman SALM (1993) Dynamic Energy Budgets in Biological Systems. Cambridge University Press, Cambridge.

Kozlowski J ( 1992) Optimal allocation of resources to growth and reproduction: implications for age and size at maturity. Trends in Ecology and Evolution 7: 15-19.

Legendre L, Legendre P (1998) Numerical Ecology, 2nd ed. Elsevier, Amsterdam, $870 \mathrm{p}$.

Legendre P, Lapointe F-J, Casgrain P (1995) Modeling brain evolution from behavior: a permutational regression approach. Evolution 18: 1,487-1,499.

Leibersperger E (1960) Die Oxyuroidea der europäischen Arthropoden. Parasitol. Schriftenr 11: 1-150.

Lewin R (1983) Santa Rosalia was a goat. Science 221: 636-639.

Maurer BA, Brown JH, Rusler RD (1992) The micro and macro in body size evolution. Evolution 46: 939-953.

May RM (1978) The dynamics and diversity of insect faunas. In: Mond LA, Waloff N (eds.) Diversity of Insect Faunas. Blackwell, New York, pp 188-204.

Morand S (1996a) Biodiversity of parasites in relation with their life cycle. In: Hochberg M, Clobert J, Barbault R (eds.) The Genesis and Maintenance of Biological Diversity. Oxford University Press, Oxford, pp. 243-260. 
Morand S (1996b) Life-history traits in parasitic nematodes : a comparative approach for the search of invariants. Functional Ecology 10: 210-218.

Naganuma KH, Roughgarden JD (1990) Optimal body size in lesser antillean Anolis lizards - a mechanistic approach. Ecological Monographs 60: 239-256.

Pagel MD, Harvey PH (1988) The taxon-level problem in the evolution of mammalian brain size: facts and artifacts. American Naturalist 132: 344-359.

Pasteur G, Bons J (1959) Les batraciens du Maroc. Travaux de l'Institut Scientifique Chérifien Sér. Zool. 17: 1-20.

Pasteur G, Bons J (1960) Catalogue des reptiles actuels du Maroc. Travaux de l'Institut Scientifique Chérifien Sér. Zool. 18: 1-25.

Pearson K (1901) On lines and planes of closest fit to systems of points in space. Philosophical Magazine Ser. 6 2: 559-572.

Peters RH (1983) The Ecological Implications of Body Size. Cambridge University Press, Cambridge.

Petter AJ, Quentin J-C (1976) Keys to the genera of the Oxyuridea, no 4. In: Anderson RC, Chabaud AG, Wilmott S (eds.) $\mathrm{CIH}$ Keys to the Nematode Parasites of Vertebrates. Commonwealth Agricultural Bureaux, Farnham Royal, Slough, pp. 1-30.

Poinar GO (1977) CIH Key to the Groups and Genera of Nematode Parasites of Invertebrates. Commonwealth Agricultural Bureaux, Farnham Royal, Slough.

Poulin R (1995a) Evolutionary influences on body size in freeliving and parasitic isopods. Biological Journal of the Linnean
Society 54: 231-244.

Poulin R (1995b) Evolution of parasite life history traits: myths and reality. Parasitology Today 11: 342-345.

Purvis A, Rambaut A (1994) Comparative Analysis by Independent Contrasts (CAIC): A Statistical Package for the Apple Macintosh Version 2.0, User's Guide. University of Oxford, Oxford.

Purvis A, Rambaut A (1995) Comparative analysis by independent contrasts (CAIC). Computer Applications in the Biosciences 11: 247-251.

Sibly RM, Calow P (1986) Physiological Ecology of Animals: An Evolutionary Approach. Blackwell, Oxford.

Skrjabin KI, Shikhobalova NP, Lagodovskaya EA (1960) Oxyurata of Animals and Man (Izd Akad Nauk SSSR Moskva, translated 1974). Israel Program for Scientific Translations, Jerusalem.

Skorping A, Read AF, Keymer AE (1991) Life history covariation in intestinal nematodes of mammals. Oikos 60:365-372.

Stanley SM (1973) An explanation for Cope's rule. Evolution 27: $1-26$.

Sokal RR, Rohlf FJ (1981) Biometry, 2nd ed. Freeman, New York.

Steams SC (1992) The Evolution of Life Histories. Oxford University Press, Oxford.

Walker EP (1968) Mammals of the World, 2nd ed. John Hopkins Press, Baltimore.

Wharton DA (1986) A Functional Biology of Nematodes. Croom Helm, London. 